\title{
An Unusual Cause of Concordance in the Setting of Left Bundle Branch Block
}

\author{
Alqaisi O, Carter J , Xu J , Paydak H and Carter \\ J H* \\ Medical Faculty/ Staff at University of Arkansas for \\ Medical Sciences, Little Rock, Arkansas, USA \\ *Corresponding author: J anice H. Carter, Medical \\ Faculty/ Staff at University of Arkansas for Medical \\ Sciences, Little Rock, Arkansas, USA
}

Received: March 02, 2021; Accepted: April 14, 2021; Published: April 21, 2021

\section{Case Presentation}

A 73-year-old female with a past medical history of atrial fibrillation, mechanical mitral valve replacement on warfarin, hypertension and hypothyroidism presented to the emergency department with a fall. She fell and hit her head upon standing up from a seated position. She reported a constant posteriorly located headache along with episodes of nausea and vomiting. She denied chest pain, shortness of breath, syncope and fever.

The initial examination showed blood pressure of $107 / 64 \mathrm{mmHg}$ respiratory rate of $13 / \mathrm{Min}$, pulse of $76 / \mathrm{Min}$, oxygen saturation of $96 \%$ and Glascow Coma Scale (GCS) of 13, verbal response 4, motor response 6 and eye response 3. Pupils were round and reactive to light. No focal weakness or sensory loss were noted. The patient's mental status and GCS progressively worsened for which she eventually was intubated.

The patient had a mild leukocytosis of $14.11 \times 10^{9}$ (4.0-10.0). Her sodium, calcium, magnesium, phosphorus and potassium were normal. International Normalized Ratio (INR) was 2.9.

The troponin upon presentation was $0.69 \mathrm{ng} / \mathrm{ml}$ and trended down throughout the hospitalization. Her EKG showed normal sinus rhythm with a left bundle branch block with ST segment elevation in leads $V_{3}-V_{5}$ and concordant ST elevation $>1 \mathrm{~mm}$ in $V_{5}$. Sgarbossa criteria for acute myocardial infarction in the presence of LBBB was 5 points.

Computed tomography (CT) scan of the head without contrast showed large bilateral cerebellar hemorrhages with mild inferior herniation of the cerebellar tonsils. Echocardiogram showed ejection fraction of $55-60 \%$ with no wall motion abnormalities.

Immediate supportive treatment, including fluids and reversal of anticoagulation with prothrombin complex concentrate and vitamin K were administered. The patient underwent a successful suboccipital decompressive craniotomy.

\section{Discussion}

The American Heart Association, American College of Cardiology, and the Heart Rhythm Society joint paper defined the criteria for complete left bundle branch block in adults as: QRS duration $\geq 120 \mathrm{~ms}$, broad notched or slurred $\mathrm{R}$ wave in leads I, aVL, $\mathrm{V}_{5}$, and $\mathrm{V}_{6}$, absent $\mathrm{q}$ waves in leads $\mathrm{I}_{1} \mathrm{~V}_{5}$, and $\mathrm{V}_{6}$ and $\mathrm{R}$ peak time greater than $60 \mathrm{~ms}$ in leads $\mathrm{V}_{5}$ and $\mathrm{V}_{6}$ but normal in leads $\mathrm{V}_{1}, \mathrm{~V}_{2}$, and $\mathrm{V}_{3}[1]$.

Criteria for diagnosing myocardial ischemia in the presence of LBBB was first introduced in 1996 by Sgarbossa and his colleagues. The criteria included ST-Segment Elevation (STE) of $1 \mathrm{~mm}$ or more that is concordant with the QRS complex, ST-segment depression of $1 \mathrm{~mm}$ or more in lead $\mathrm{V}_{1}, \mathrm{~V}_{2}$, or $\mathrm{V}_{3}$; and ST-segment elevation of $5 \mathrm{~mm}$ or more that was discordant with the QRS complex [2].

A modified Sgarbossa criteria has emerged in which the third aforementioned criteria was replaced by; $\geq 1$ lead anywhere with $\geq 1 \mathrm{~mm}$ STE and proportionally excessive discordant STE, as defined by $\geq 25 \%$ of the depth of the preceding S-wave. The modified Sgarbossa criteria was shown to be both more sensitive and overall superior to the original criteria for identifying acute coronary occlusion in LBBB $[3,4]$.

"Cerebral T waves" is a historically known entity for more than five decades that describes $\mathrm{T}$ wave inversion in the presence of increased intracranial pressure. One explanation for this phenomenon could be attributed to myocardial injury secondary to local sympathetic stimulation. Although the real cause behind it remains unknown $[5,6]$.

In this case, we present an ECG with left bundle branch block in the setting of concordant ST elevation in leads $\mathrm{V}_{3}-\mathrm{V}_{5}$. This electrocardiogram demonstrated a unique case of concordance between the QRS complex and the STE in lead $V_{5}$ and symmetric $\mathrm{T}$-wave inversion in $\mathrm{V}_{4}-\mathrm{V}_{6}$ that does not signal ischemia or injury. However, the underlying cause of the patient's aforementioned ECG was later found to be symmetric $\mathrm{T}$ wave inversion secondary to increased intracranial pressure after carefully reviewing the history. Concordant ST segment elevation in V5 can also be due to intracranial bleeding. There are currently no documented cases of left bundle branch block with concordant ST segment elevation secondary to increased intracranial pressure. The underlying mechanism is unknown at this time.

\section{References}

1. Surawicz B, Childers R, Deal BJ \& Gettes LS. AHA/ACCF/HRS recommendations for the standardization and interpretation of the electrocardiogram: Part III: Intraventricular conduction disturbances: A scientific statement from the American Heart Association Electrocardiography and Arrhythmias Committee, Council on Clinical Cardiology; the American College of Cardiology Foundation; and the Heart Rhythm Society: Endorsed by the International Society for Computerized Electrocardiology. Circulation. 2009; 119: e235-e240.

2. Liron M. Electrocardiographic diagnosis of acute myocardial infarction in the presence of left bundle-branch block. N. Engl. J. Med. 1996; 335: 131-132.

3. Smith SW, Dodd KW, Henry TD, Dvorak DM \& Pearce LA. Diagnosis of ST-
J Fam Med - Volume 8 Issue 2 - 2021

ISSN : 2380-0658 | www.austinpublishing group.com

Carter et al. (C) All rights are reserved
Citation: Alqaisi O, Carter J, Xu J, Paydak H and Carter JH. An Unusual Cause of Concordance in the Setting of Left Bundle Branch Block. J Fam Med. 2021; 8(2): 1245 
elevation myocardial infarction in the presence of left bundle branch block with the ST-elevation to S-wave ratio in a modified sgarbossa rule. Ann. Emerg. Med. 2012; 60: 766-776.

4. Pendell Meyers $\mathrm{H}$, et al. Validation of the modified Sgarbossa criteria for acute coronary occlusion in the setting of left bundle branch block: A retrospective case-control study. Am. Heart J. 2015; 170: 1255-1264.
5. Gregory $T$ \& Smith M. Cardiovascular complications of brain injury. Contin. Educ. Anaesthesia, Crit. Care Pain. 2012; 12: 67-71.

6. Levis JT. ECG Diagnosis: Deep T Wave Inversions Associated with Intracranial Hemorrhage. Perm. J. 2017; 21. 